\title{
Identificando elementos do cuidado centrado na pessoa: estudo qualitativo a partir da perspectiva de pacientes hospitalizados
}

\author{
Identifying elements of person-centred care: qualitative \\ study from the perspective of hospitalized patients
}

\author{
Veluma de Sousa Wanderley ${ }^{1}$, Karla Fernanda Gonçalves de Araújo², \\ Matheus Medeiros de Morais Santos², José Luis Simões Maroja ${ }^{3}$, \\ Rilva Lopes de Sousa Muñoz ${ }^{4}$
}

\section{Resumo}

Os objetivos deste estudo foram analisar as percepções de doentes internados em enfermarias de clínica médica de um hospital universitário em relação aos médicos que os atendiam, assim como se tais percepções se enquadravam nos conceitos do método clínico centrado na pessoa ou no modelo biomédico. Um estudo descritivo, de abordagem qualitativa, baseada na técnica de análise de conteúdo foi desenvolvido. Realizaram-se entrevistas individuais com 11 pacientes através de guia com perguntas abertas. Foram observadas narrativas relacionadas ao exame clínico e exames complementares. Os discursos revelam gratidão, satisfação com a atenção do médico e com a descoberta do diagnóstico. Observaram-se discursos que mostraram uma comunicação sobre o diagnóstico e a terapêutica entre o médico e o paciente, com discussão do que seria necessário para o melhor tratamento, conforme preconiza o método clínico centrado na pessoa, embora não tenha havido menção ao compartilhamento de tomadas de decisão. Observou-se que o saber médico teve uma posição de superioridade com relação ao dos pacientes, que assumiram atitude passiva, alguns deles não identificando qual era seu principal médico e com pouco entendimento sobre seus diagnósticos pela ausência de linguagem acessível, características que se enquadram no modelo biomédico. Como conclusão, as falas dos entrevistados mostraram que grande parte se sentiu bem atendida e revelou confiança e satisfação, havendo alocuções compatíveis com o método clínico centrado na pessoa. Contudo, não houve narrativas sugestivas de sua participação ativa nas decisões tomadas, observando-se, nesse aspecto, uma relação centrada no médico e/ou na doença.

Palavras-chave: Assistência centrada no paciente. Pacientes internados. Pesquisa qualitativa.

\footnotetext{
${ }^{1}$ Graduanda em Medicina na Universidade Federal da Paraíba (UFPB), João Pessoa, Paraíba, Brasil. E-mail: velumasw@gmail.com

${ }^{2}$ Graduandos em Medicina na Universidade Federal da Paraíba, João Pessoa, Paraíba, Brasil.

${ }^{3}$ Especialização em Administração em Serviços de Saúde pela Universidade de Ribeirão Preto (Unaerp), Ribeirão Preto, São Paulo, Brasil. Professor do Departamento de Medicina Interna do Centro de Ciências Médicas da Universidade Federal da Paraíba, João Pessoa, Paraíba, Brasil.

${ }^{4}$ Doutorado em Produtos Naturais e Sintéticos Bioativos pela Universidade Federal da Paraíba, João Pessoa, Paraíba, Brasil. Professora do Departamento de Medicina Interna do Centro de Ciências Médicas da Universidade Federal da Paraíba, João Pessoa, Paraíba, Brasil.
} 


\begin{abstract}
The aims of this study were to analyze the perceptions of patients hospitalized in medical clinic wards of a university hospital regarding the physicians who attended them, as well as whether such perceptions fit the concepts of the person-centered clinical method or the biomedical model. A descriptive, qualitative approach based on the technique of content analysis was developed. Individual interviews with 11 patients were conducted through an open question guide. Narratives related to clinical examination and complementary tests were observed. The speeches show gratitude, satisfaction with the physician's attention and the discovery of the diagnosis. The researchers observed speeches which showed a communication about the diagnosis and therapy between the doctor and the patient, discussing what would be necessary for the best treatment, as recommended by the personcentered clinical method, although there was no mention of a shared decision-making. It was observed that medical knowledge had a position of supremacy regarding the patients, who assumed a passive attitude, some of them not identifying who was their main doctor and with little understanding about their diagnoses due to the absence of accessible language, features that fit the biomedical model. As a conclusion, the interviewees' statements show that a great part of them felt well attended and revealed confidence and satisfaction, having speeches compatible with the person-centered clinical method. However, there were no suggestive narratives of their active participation in the decisions made, so, it was observed, in this regard, a relationship centered on the doctor and / or the disease.
\end{abstract}

Keywords: Patient-centered care. Inpatients. Qualitative research.

\section{Introdução}

A relação médico-paciente é considerada um aspecto-chave para a melhoria da qualidade dos serviços de saúde e desdobra-se em diversos componentes importantes, como a personalização da assistência, a humanização do atendimento e o direito à informação. ${ }^{(1)}$ Contudo, os modelos de prática clínica observados na medicina influenciaram de modos diversos a relação do doente com o médico ao longo dos tempos. O denominado modelo biomédico, de natureza cartesiana e com enfoque na doença, persiste como abordagem predominante na prática clínica ocidental, embora tenha se revelado insuficiente pela exclusão de aspectos essenciais do processo de adoecimento do indivíduo. ${ }^{(2)}$

No modelo biomédico, entende-se a doença em termos do quadro clínico de referência, uma interpretação que muitas vezes tem pouca relação com a experiência real do doente. Tal modelo provocou questionamentos, promovendo o surgimento do modelo biopsicossocial, que incorpora o caráter subjetivo, psicológico e social da doença, contemplando a pessoa. Nesse sentido, uma das abordagens atualmente propostas para alcançar essa compreensão é o método clínico centrado na pessoa (MCCP), considerado um "novo método clínico", (3) identificado como elemento central dos cuidados de saúde de qualidade no século XXI, ${ }^{(4)}$ representando também um imperativo ético para a profissão médica. ${ }^{(5)}$ Com essa nova tendência, está havendo uma mudança no papel atribuído aos pacientes, que passam a ser o foco da atenção, paralelamente à existência de uma parceria com os profissionais de saúde, ao invés de aqueles serem vistos apenas como receptores passivos do cuidado. ${ }^{(6)}$

Embora não haja consenso sobre a definição do MCCP, a sua essência consiste na tentativa de entender a experiência da doença a partir do ponto de vista do doente. Stewart e seus colaboradores ${ }^{(7)}$ desempenharam um papel importante na conceitualização do MCCP, que foi desenvolvido inicialmente na década de 1980 e descrito em 1995, ${ }^{(8)}$ como um tipo de abordagem mais estudada na área de medicina de família e comunidade. $^{(9-10)}$ Em sua última atualização, ${ }^{(11)}$ propõem-se quatro (4) dimensões no MCCP: (1) explorando a saúde, a doença e a experiência 
de doença; (2) compreendendo a pessoa como um todo; (3) elaborando um plano conjunto de manejo dos problemas; e (4) intensificando a relação entre a pessoa e o médico.

Considera-se, entretanto, que essa abordagem do cuidado centrado no paciente deve ser estudada no âmbito do hospital também, e não ser voltada apenas a pacientes da atenção primária à saúde. Quando se pensa a respeito dos hospitais, como setor de média e alta complexidade na área da saúde, reporta-se à ideia de um serviço cuja prática profissional é distante dos moldes de humanização e de integração médico-paciente. ${ }^{(12)}$ Além disso, durante a hospitalização, os doentes enfrentam uma situação de crise e vulnerabilidade, em um ambiente estranho, cercado de pessoas não conhecidas, podendo encarar o que se denomina de despersonalização pessoal e espacial. ${ }^{(13)}$ A palavra "humanização" passou a ser utilizada para nomear a tendência de diálogo e clareza com que as informações são transmitidas ao paciente. ${ }^{(14)}$ No ano 2000, o Ministério da Saúde (MS) criou o Programa Nacional de Humanização da Assistência Hospitalar, ${ }^{(15)}$ com o objetivo de promover essa nova cultura de atendimento no âmbito dos hospitais, seja pelo cuidado ou relação com o paciente e, apenas posteriormente, esse programa se estendeu para toda a rede de atenção à saúde.

Compreender como os pacientes internados enfrentam a hospitalização, o adoecimento e a equipe de saúde pode ser um conhecimento valioso para o aperfeiçoamento da prática profissional. Assim, as perguntas desta pesquisa são as seguintes: "quais são as percepções de pacientes internados em enfermarias de um hospital universitário sobre os médicos que os atendem? Essas visões dos enfermos se enquadram mais no modelo biomédico ou no modelo clínico centrado na pessoa?".

Os objetivos deste estudo foram analisar as percepções dos doentes internados em enfermarias de clínica médica do Hospital Universitário Lauro Wanderley (HULW) em relação aos médicos que os atendem, assim como se tais visões dos pacientes se enquadram nos conceitos do método clínico centrado na pessoa.

\section{Material e Método}

O modelo deste estudo foi descritivo, de abordagem qualitativa, com enquadramento metodológico baseado na análise temática de conteúdo. Os dados foram obtidos através de entrevistas abertas, realizadas individualmente. A amostragem foi não-probabilística por conveniência, com recrutamento de pacientes que se encontravam internados nas enfermarias de clínica médica do HULW no período da coleta dos dados (setembro a outubro de 2016). Avaliaram-se 11 (onze) indivíduos, com fechamento amostral por saturação, suspendendo-se a inclusão de novos participantes quando os dados obtidos passaram a apresentar repetição, na avaliação dos pesquisadores, conforme é preconizado por trabalho anterior a este. ${ }^{(16)} \mathrm{O}$ presente estudo faz parte de um projeto mais amplo sobre as representações sociais dos pacientes internados no HULW a respeito dos seus médicos assistentes durante a hospitalização.

O HULW é um hospital de médio porte, realizando em torno de 20 mil atendimentos, 250 cirurgias por mês e polarizando serviços para todos os municípios do estado da Paraíba. É um serviço de saúde de referência no estado, sendo habilitado no Cadastro Nacional de Estabelecimentos de Saúde (CNES) como unidade de alta complexidade em atendimento terciário. O HULW, como hospital universitário, cede espaços de prática para alunos das graduações de Ciências da Saúde, além de abrigar mais de 20 programas de residência médica e multiprofissional.

Incluíram-se neste estudo os pacientes com idade igual ou superior a 18 anos, de ambos os sexos, internados nas enfermarias de clínica médica do HULW com permanência hospitalar superior a 72 horas, em condições físicas e psicológicas favoráveis à expressão verbal e interessados em compartilhar as experiências vividas.

Os procedimentos de coleta dos dados foram executados por um professor de Semiologia Médica da Universidade Federal da Paraíba (UFPB) e duas estudantes de Medicina dessa universidade, aquele 
entrevistando os pacientes e estas dando suporte e tomando notas de campo. Os indivíduos foram convidados a participar da pesquisa, solicitandose sua assinatura no TCLE. Após essa abordagem inicial, preencheu-se um formulário para registro de dados sociodemográficos (idade, escolaridade, sexo, procedência e profissão) e clínicos (hipótese diagnóstica principal registrada no prontuário e tempo de internação). Posteriormente, foi realizada uma entrevista semiestruturada a partir de um guia elaborado pelos autores, com registro em áudio consentido pelos entrevistados.

$O$ guia de entrevista enfocou as seguintes questões: (1) a percepção dos pacientes sobre o interesse profissional demonstrado em relação ao entrevistado pelo seu principal médico assistente durante a internação; (2) a opinião dos enfermos sobre a capacidade do médico e sua confiança neste; (3) a compreensão do interesse do médico em seu modo de vida; (4) se os doentes sentiam que o médico entendia seu problema; e (5) se havia satisfação com a informação recebida do médico sobre o seu diagnóstico e tratamento. Interrogouse também se os indivíduos sabiam identificar seu principal médico assistente dentro da equipe que os assistia. Os itens que compuseram o questionário basearam-se em adaptação do instrumento "Registro do Atendimento Clínico Centrado na Pessoa" empregado em estudo recente. ${ }^{(17)}$ Registraram-se características sociodemográficas dos participantes (idade, procedência, sexo, ocupação, escolaridade) e hipótese diagnóstica à admissão hospitalar.

As entrevistas foram realizadas em sala adjacente às enfermarias de clínica médica do HULW, de forma privativa e sem interrupções. Cada interlocução foi conduzida em um diálogo aberto pelo entrevistador e durou entre 30 e 60 minutos. Utilizou-se a expressão "percepção do paciente" para se referir ao processo observado pelos enfermos, incluindo experiências subjetivas e objetivas expressas verbalmente. ${ }^{(18)}$ As conversas foram gravadas, transcritas na íntegra, com correção dos erros gramaticais e identificadas mediante números pela ordem de realização: ENT. 01, ENT. 02, e assim sucessivamente.
As transcrições dos diálogos e as notas de campo constituíram os dados brutos com os quais se estudaram as unidades de análise de acordo com alguns critérios metodológicos, ${ }^{(19)}$ que compreenderam os seguintes passos: organização dos dados coletados, leitura e releitura do material, codificação e categorização. Por fim, o conteúdo foi articulado com o referencial teórico adotado para problematizar e ampliar o conhecimento acerca da visão dos respondentes sobre seus médicos. Utilizou-se a técnica de análise de conteúdo temática convencional, referência nos trabalhos de análise de conteúdo, ${ }^{(20)}$ para determinar os principais temas presentes nas respostas das entrevistas.

Primeiramente, os dados foram limpos removendo-se respostas em texto livre que não continham informações relevantes para a análise de conteúdo, como respostas monossilábicas e os itens de dados sociodemográficos. Posteriormente, foi conduzida a codificação, com recorte, agregação e enumeração. Identificaram-se as categorias iniciais que refletiram temas salientes e recorrentes nos dados, que foram agrupadas por condensação, ${ }^{(21)}$ à luz das premissas do "método clínico centrado no paciente" (Quadro 1) e outros referenciais teóricos relacionados a partir dos temas encontrados. ${ }^{(11)}$ Contudo, as categorias utilizadas foram apriorísticas, pois foram pré-definidas pelo modelo fechado da teoria que embasa a análise.

Duas autoras (estudantes de graduação em Medicina) atuaram como codificadoras (VSW e KFGA), trabalhando de forma independente para garantir que o número máximo de temas fosse identificado, lendo e relendo as transcrições das entrevistas e usando palavras-chave, frases e parágrafos. Estes foram comparados por sua semelhança de significados relacionados e por suas diferenças, retornando-se ao texto original. Ao final, três sessões de verificação dos dados foram realizadas, em que outros dois colaboradores (JLSM e RLSM) reuniram-se com as duas primeiras pesquisadoras para revisar a codificação, chegando-se a um consenso sobre a aplicação dos códigos criados. Por fim, a última autora revisou 
as transcrições codificadas para verificação final de que todos os aspectos das entrevistas referentes aos códigos tivessem sido capturados.
A seguir, demonstram-se as categorias e subcategorias do MCCP empregadas na codificação das unidades de análise (Quadro 1).

Quadro 1 - Quadro de codificação com categorias e subcategorias do referencial teórico “método clínico centrado na pessoa".

\begin{tabular}{|c|c|}
\hline Categorias & Subcategorias \\
\hline $\begin{array}{l}1 \text { - Exploração da doença e a experiência da pessoa } \\
\text { com a doença. }\end{array}$ & $\begin{array}{l}\text { 1.1 Avaliação da história, exame físico e exames } \\
\text { complementares. } \\
\text { 1.2 Avaliação da dimensão da doença: } \\
\text { sentimentos, ideias, efeitos sobre a } \\
\text { funcionalidade e expectativas da pessoa. }\end{array}$ \\
\hline 2 - Entendimento da pessoa como um todo. & $\begin{array}{l}\text { 2.1 A pessoa: sua história de vida, aspectos } \\
\text { pessoais e de desenvolvimento. } \\
\text { 2.2 Contexto próximo: família, comunidade, } \\
\text { emprego, suporte social. } \\
\text { 2.3 Contexto distante: comunidade, cultura, } \\
\text { ecossistema. }\end{array}$ \\
\hline 3 - Elaboração de um plano comum de manejo. & $\begin{array}{l}\text { 3.1 Avaliação dos problemas e prioridades. } \\
\text { 3.2 Estabelecimento de objetivos para o tratamento } \\
\text { e manejo. } \\
\text { 3.3 Avaliação e estabelecimento dos papeis } \\
\text { da pessoa e do profissional de saúde. }\end{array}$ \\
\hline 4 - Fortalecimento da relação médico-pessoa. & $\begin{array}{l}\text { 4.1 Exercendo a compaixão. } \\
\text { 4.2 Relação de Poder. } \\
\text { 4.3 A cura (efeito terapêutico da relação). } \\
\text { 4.4 O autoconhecimento. } \\
\text { 4.5 A transferência e contratransferência. }\end{array}$ \\
\hline
\end{tabular}

Fonte: Stewart et al. ${ }^{(7)}$

Em contraposição, foram considerados significados relacionados ao modelo biomédico ${ }^{(22)}$ quando havia presença das seguintes características: modelo paternalista centrado no médico, em que o último exerce autoridade; intervenções focadas na doença; práticas de cuidados concentradas nos diagnósticos e tratamentos das doenças; ênfase no uso de tecnologias e exames complementares; ausência de compreensão da natureza multidimensional do ser humano; falta de integração entre níveis primário, secundário e terciário de cuidado; não reconhecimento da natureza multifatorial das doenças; dicotomia entre a mente e o corpo.

Foi feito o cálculo das frequências das respostas às perguntas, considerando afirmativas e negativas aos questionamentos do guia de entrevista, sendo apresentadas em tabelas. Através do software NVivo 12, aplicativo de gerenciamento e análise de dados qualitativos, visualizaramse os termos mais utilizados e suas respectivas frequências, gerando-se um diagrama do tipo "nuvem de palavras", que organiza as expressões conforme o número de vezes que aparecem no texto, apresentando-as em maior tamanho ou menor de acordo com a frequência do vocábulo no texto, visando-se à exposição mais direta e objetiva das informações.

Este projeto foi aprovado pelo Comitê de Ética em Pesquisa do HULW, sob o título "Representações Sociais de Pacientes Sobre o Médico: Um Estudo com Pacientes Internados 
na Clínica Médica do Hospital Universitário da UFPB", com CAAE no 57896816.0.0000.5183 e número de parecer 1.714.550, de 06/09/2016.

\section{Resultados}

Realizaram-se entrevistas individuais com 11 pacientes internados nas enfermarias de clínica médica do HULW entre os meses de outubro e novembro de 2016. Os participantes foram predominantemente do sexo masculino, com idades entre 22 e 69 anos (82\% acima de 40 anos), não alfabetizados ou com escolaridade fundamental incompleta e apresentando tempo de internação, no momento da entrevista, variando de 2 a 30 dias (Quadro 2).

Quadro 2 - Características sociodemográficas e hipótese diagnóstica (n=11), João Pessoa, Paraíba, de setembro a outubro de 2016.

\begin{tabular}{|c|c|c|c|c|c|c|}
\hline Entrevista & $\begin{array}{l}\text { Idade } \\
\text { (anos) }\end{array}$ & Procedência & Sexo & Ocupação & Escolaridade & $\begin{array}{l}\text { Hipótese } \\
\text { diagnóstica }\end{array}$ \\
\hline E1 & 45 & João Pessoa - PB & Masculino & Mecânico & $\begin{array}{c}\text { Médio } \\
\text { incompleto }\end{array}$ & $\begin{array}{l}\text { Insuficiência } \\
\text { cardíaca }\end{array}$ \\
\hline E2 & 50 & Jacaraú - PB & Masculino & Agricultor & $\begin{array}{c}\text { Não } \\
\text { alfabetizado }\end{array}$ & Piodermite \\
\hline E3 & 42 & - & Feminino & Agricultora & $\begin{array}{c}\text { Não } \\
\text { alfabetizada }\end{array}$ & $\begin{array}{l}\text { Insuficiência } \\
\text { cardíaca }\end{array}$ \\
\hline E4 & 60 & São Mamede - PB & Feminino & Agricultora & $\begin{array}{l}\text { Fundamental } \\
\text { incompleto }\end{array}$ & Anemia \\
\hline E5 & $40 \mathrm{a}$ & - & Feminino & $\begin{array}{l}\text { Empregada } \\
\text { doméstica }\end{array}$ & $\begin{array}{l}\text { Fundamental } \\
\text { Incompleto }\end{array}$ & Endocrinopatia \\
\hline E6 & 49 & João Pessoa - PB & Masculino & Propagandista & Fundamental & Hepatopatia \\
\hline E7 & 69 & Santa Rita - PB & Feminino & Agricultora & $\begin{array}{c}\text { Não } \\
\text { alfabetizada }\end{array}$ & $\begin{array}{l}\text { Infecção } \\
\text { urinária }\end{array}$ \\
\hline E8 & 39 & - & Masculino & Vaqueiro & $\begin{array}{l}\text { Fundamental } \\
\text { incompleto }\end{array}$ & Coagulopatia \\
\hline E9 & $22 \mathrm{a}$ & Sapé - PB & Feminino & Estudante & $\begin{array}{l}\text { Superior } \\
\text { incompleto }\end{array}$ & Pneumonia \\
\hline E10 & 41 & Lagoa do Félix - PE & Masculino & Agricultor & $\begin{array}{c}\text { Não } \\
\text { alfabetizado }\end{array}$ & Mielopatia \\
\hline E11 & 47 & Bayeux - PB & Masculino & $\begin{array}{c}\text { Auxiliar de } \\
\text { serviços gerais }\end{array}$ & Superior & Miocardiopatia \\
\hline
\end{tabular}

Fonte: Dados primários da pesquisa, 2016/2017

Dentro do compilado das transcrições e que acreditavam na capacidade deste, assim constatou-se que $90,9 \%$ dos pacientes disseram como achavam que ele compreendia seu problema confiar no seu médico assistente da enfermaria, (Tabela 1). 
Tabela 1 - Frequências de respostas afirmativas ao questionário sobre a percepção dos pacientes sobre a figura do médico (n=11), João Pessoa, Paraíba, de setembro a outubro de 2016.

\begin{tabular}{lcc}
\hline \multicolumn{1}{c}{ Variáveis } & \multicolumn{2}{c}{ Frequências } \\
\cline { 2 - 3 } & F & \% \\
\hline Percebe o médico como competente/capaz. & 10 & 90,9 \\
Percebe que o médico compreende seu problema. & 10 & 90,9 \\
Recebeu informações do médico sobre seu diagnóstico. & 9 & 81,8 \\
Recebeu informações do médico sobre seu tratamento. & 9 & 81,8 \\
Percebe que o médico se interessa pelo seu modo de vida. & 8 & 72,7 \\
Percebe que o médico se interessa por ele (a) como pessoa. & 8 & 72,7 \\
Sabe identificar qual é o seu médico na equipe. & 8 & 72,7 \\
Sentiu-se satisfeito (a) com as informações recebidas. & 8 & 72,7 \\
\hline
\end{tabular}

Fonte: Dados primários da pesquisa, 2016/2017

$\mathrm{Na}$ análise das transcrições, emergiram do corpus das 11 narrativas, unidades de categorias temáticas do método clínico centrado na pessoa e de seu contraponto teórico, o "modelo biomédico". Uma breve descrição dos conteúdos temáticos acompanhando as respectivas citações ilustrativas será fornecida nos próximos parágrafos.

\section{1 - Exploração da doença e a experiência da pessoa com a doença}

Nesta categoria, foram observadas narrativas relacionadas ao exame clínico (história e exame físico) e exames complementares (sem ênfase nestes últimos), em que os discursos mostraram como o paciente concebia a investigação da sua doença. Os discursos obtidos revelam gratidão, assim como a satisfação em relação à atenção do médico e com a descoberta do diagnóstico de sua doença:

Para mim ela deu o diagnóstico certo do que eu tinha. 'Tá' entendendo? 'Olha, seu A., seu diagnóstico é esse...', ela foi sincera. (E1).

Agradeço muito, muito mesmo porque eu não sabia o que é que estava acontecendo comigo, não é?... [...]. Ela disse assim: 'vamos fazer outros exames para saber o que é que você está sentindo [...]'. (E5).
Aqui estão vendo a necessidade que a gente tem de descobrir o que realmente a gente está sofrendo, o tipo de doença que está sofrendo [… . (E11).

Também houve discursos que revelaram que os pacientes se sentiram compreendidos e satisfeitos por terem sido questionados sobre seus sintomas e examinados adequadamente:

Mas ele me escuta, me senta na cama, bate nas costas, tudo é uma beleza mesmo! (E7).

Ai ele olhou meu corpo todo, olhou essas manchas no couro, e ai disse que as taxas do sangue estavam baixas [...]. (E8).

Eu digo sinto isso, ele aperta e pergunta se dói. Dói [...]. (E10).

[O médico] parece [compreender o que ele, o paciente, está sentindo], que eu passo tudo pra ele. Eu digo para ele... Olhe, eu estou sentindo uma câimbra... Estou sentindo uma dor muito forte [...]. (E11).

Na subcategoria de avaliação da dimensão da doença, ou seja, sentimentos, ideias, efeitos sobre a funcionalidade e expectativas da pessoa, representando como os pacientes vivenciavam sua 
doença, ou como a enfermidade interferia em suas questões subjetivas, observaram-se as seguintes falas:

Então eu fiquei triste, por um lado, porque vou fazer cirurgia, e feliz por outro, porque descobriram [o diagnóstico], e após a cirurgia eu vou ficar bom. (E1).

Foi ela que falou o que eu tinha. Meu estado de saúde, eu estou achando ótimo... Porque eu estava mal mesmo, mal mesmo... Lá era só 'tome remédio, tome remédio' e nada de eu ficar boa [...]. (E2).

Eu acho que [a médica] entende [o meu problema de saúde] porque eu estou melhorando. (E3).

É... Porque se não fosse isso, eu não estava nem boa, não é? Eu estava até do mesmo jeito que eu cheguei aqui [...]. Já estou outra pessoa. (E5).

Eu cheguei aqui de cadeira de rodas, hoje estou aqui andando em todo canto [...]. (E10).

Em vez de ser o que eu suspeitava que era a questão do pulmão... Mas não, é coração. (E11).

\section{2 - Entendimento da pessoa como um todo}

$\mathrm{Na}$ subcategoria da história de vida do indivíduo, contendo aspectos pessoais e de desenvolvimento, uma paciente descreveu o seu comportamento no ambiente familiar, indicando que o médico demonstrou interesse por sua vida pessoal, buscando uma compreensão holística do seu processo de adoecimento:

Porque ela perguntou a mim como era lá em casa, com o trabalho, com minha família e tudo isso eu expliquei a ela... O que en era em casa... Uma pessoa muito agitada, qualquer coisinha já estava brigando com o pessoal, com meu esposo [...]. (E5).

No contexto próximo, representado pela família, comunidade, emprego e suporte social, em que esse cenário seria um fator preponderante no entendimento da integralidade do indivíduo e o quanto isso interferia na origem e na manifestação da doença, emergiram dos discursos as seguintes falas:

Chegou uma médica que perguntou se eu criava animal lá, se eu criava gato lá em casa, se eu criava cachorro dentro de casa... Ai eu disse: 'Não, doutora, eu não crio gato lá em casa não, porque minha mulher tem alergia $[\ldots]^{\prime}$. (E8).

Ele perguntou se eu mexia com veneno. Ai eu disse a ele que eu não mexia com veneno não... Agora sempre colocam no lombo lá do gado da fazenda. (E8).

Sim [o médico procurou saber sobre], o relacionamento em casa, familiar.. Procuraram saber até a questão dessa minha doença que, justamente, é de família. E a preocupação deles também é chamar o pessoal da família para fazer uma entrevista e ver alguns exames para comparar com os meus. (E11).

Perguntou. Antigamente a casa era de barro, mas agora é de tijolo, tem piso, colocou telha nova, é bem bonitinha [...]. (E3).

Em relação ao ecossistema,

Você usava proteção na lida? Eu disse: usava não, doutor! E ele disse que o bafo do veneno pode ter intoxicado meu sangue. (E8).

No contexto distante, ou seja, comunidade e cultura, não foram observadas narrativas explicitamente manifestas.

\section{3 - Elaboração de um plano comum de manejo}

$\mathrm{Na}$ avaliação dos problemas e prioridades, observaram-se discursos que mostraram uma comunicação direta sobre o diagnóstico e a terapêutica entre o médico e o paciente, nos dois sentidos, com discussão do que seria necessário para o melhor tratamento, embora não tenham se referido ao real compartilhamento de tomada de decisão, como: 
Para mim ela deu o diagnóstico certo do que eu tinha. 'Tá' entendendo? 'Olha, seu A., seu diagnóstico é esse...', ela foi sincera. Só se resolve com cirurgia [...]. (E1).

Estou querendo fazer logo a biópsia, para saber como é que vai ser... Se vou me operar ou se o remédio vai desmanchar, sabe...? (E3).

Ela disse: você está com cirrose. Aí eu disse: tem cura, doutora? Ela disse: tem não. A cura vai ser você mesmo. Vai depender de você. (E6).

A médica já conversou isso tudinho comigo. (E8).

Eu passo tudo pra ele, eu digo pra ele [...]. (E11).

Ela disse: só se resolve com cirurgia. Porque não foi só ela que disse, foi um 'bocado' de médico! (E1).

Não foram observadas falas relacionadas a um planejamento conjunto do que se almejava com o tratamento no estabelecimento de objetivos para a terapêutica. Também não foram encontradas narrativas sobre avaliação e estabelecimento da decisão pela própria pessoa do paciente, mas somente por parte do médico.

\section{4 - Fortalecimento da relação médico-pessoa}

Na subcategoria “exercendo a compaixão", os discursos encontrados sugerem a existência de uma relação médico-paciente satisfatória, juntamente com uma postura de sensibilidade dos médicos frente aos problemas e necessidades do indivíduo.

Porque o atendimento... Inclusive das enfermeiras e dos médicos, é muito cortês, é um atendimento que ela lhe trata bem... $E$ tudo no padrão. (E1).

Quando eu estou lá sempre ela [a médica] liga pra mim... Manda recado... Dia desses eu disse que estava inchando e ela falou: diga a ela que venha, antes que inche mais [...]. (E3).

Aí, o doutor disse: 'fique com medo não, rapaz, você está com medo, é?... Rapaz, não fique com medo, não, que a gente está aqui para sair com a saúde [...]'. (E8).

Eles estão atendendo bem demais, não é?... A pessoa amanhece o dia, eles já estão em cima da gente atendendo quando a gente precisa. (E8).

Antes de eu vir para cá, eu fiquei em casa; ai eu tive que ligar para ele [o médico], para o Dr. A. para conseguir uma vaga, e ele, com certeza, arrumou. Eu fiquei três dias na UPA esperando vaga, mas mesmo assim ele arrumou um jeito de me trazer pra cá, porque eu não podia continuar na UPA. (E9).

Muito satisfeito! Muito satisfeito mesmo... Eu rodei esses hospitais aí e fui desprezado, sabe?... Mas quando eu cheguei aqui, eu até chorei aqui dentro do quarto... Pelo atendimento que... Não tem comparação! (E1).

$\mathrm{Na}$ subcategoria "a relação de poder", o saber técnico parece proporcionar uma posição de superioridade do médico com relação ao paciente, que assume uma posição passiva, demonstrada nos seguintes discursos:

Confio. Primeiramente, Deus; segundo, eles [os médicos]. (E7).

Isso aí eu não sei dizer não [sobre o seu problema de saúde]... Só Deus e eles [os médicos] é que sabem. (E7).

Confio plenamente [no médico]. Se eu não confiasse, ia fazer o quê? (E10).

Quanto aos aspectos relacionados à cura (o efeito terapêutico da relação médico-paciente), diversos discursos demonstram a satisfação dos enfermos em perceber uma postura de empatia dos médicos:

Porque ela [a médica] vem, conversa comigo, pergunta como eu estou [...], aí eu acho que ela se importa comigo[...]. (E5).

Assim... Porque uma médica assim... É bom, porque ela é uma pessoa doce; ela liga pra gente, ela conversa com o paciente, ela vai onde você está... Tudo isso. (E5). 
A boca e as coisas que ela faz, combinam. [...], mas eu estou muito agradecida pelo que fizeram por mim. (E5).

Todo dia de manhã ele chega logo cedo, vai logo lá onde eu estou, pergunta se eu estou bem, me examina, pergunta se eu dormi bem [...]. (E6).

É um cara bem-educado [o médico], bem legal comigo, me dá bastante atenção. Ele fica até contente quando chega visita pra mim [...]. (E6).

Os médicos são umas maravilhas, maravilhas mesmo! [...]. (E7).

Aí o doutor também disse: qualquer coisa, me procure ali, que estou ali e você me procura [...], mas você não quer uma comidinha mais maneirinha, porque você não tem dentes, não é? (E8).

Falas relacionadas ao autoconhecimento, transferência e contratransferência apresentaram superposição com as descritas anteriormente, como as mencionadas na subcategoria do efeito terapêutico da relação médico-paciente.

\section{Modelo biomédico}

Nesta categoria, encontram-se discursos que fazem um contraponto ao MCCP, enquadrandose nas características já mencionadas do modelo biomédico.

No discurso a seguir é descrita a busca incessante pelo agente etiológico através de exames, com repetição ou excesso de exames complementares, mas que foi interpretada pelo paciente como o "importar-se" do médico:

Ele disse que até segunda-feira ia fazer mais exames meus. Ai pediu outros raios-X. (E8).

Se ele [o médico] não se importasse, ele não ia procurar fazer mais exames, mais e mais para descobrir a realidade do que está grave, do que aconteceu, não é? (E11).

No modelo biomédico o entendimento do paciente sobre a sua doença não é um aspecto prioritário, já que o foco é a doença e, portanto, não existe interesse em desenvolver um plano terapêutico conjunto. Nos discursos a seguir, claramente não houve entendimento por parte dos pacientes sobre a razão para a permanência no hospital.

Só que eu queria que ele passasse uns remédios para mim, para eu tomar em casa, não é? Não queria ficar aqui não. Já faz 15 dias amanhã que estou aqui. (E4).

Eu queria saber sobre o meu problema... Porque eu não sei, não é?... Porque se nada der certo, eu vou pra casa. (E4).

Deveria chamar para conversar, explicar como é que é... Eu queria ir para casa [...]. (E2).

Nos discursos a seguir ilustra-se o pouco entendimento dos pacientes com relação às suas doenças e diagnósticos, mostrando que os médicos não se preocuparam em usar uma linguagem suficientemente acessível, assim como o tratamento não foi discutido com eles, parecendo ter sido imposto.

[...] É uma doença complicada danada, com um nome bem 'invocado', que ele disse que ia fazer essa biópsia, se for o caso de fazer cirurgia, aí eu seria transferido para Pernambuco, para Recife, porque aqui não fazia. (E6).

Ele [o médico] disse mais ou menos o nome da doença... Disse que era na medula e, assim, no espinhaço, mas eu não sei como é que é [...]. (E10).

Compreendi. Agora, só que a gente fica meio leigo porque a gente não entende muito a linguagem do médico, não é...? (E11).

O próprio paciente passa a enxergar esse modelo como algo natural e o mais apropriado para o seu cuidado, acreditando que o exame e o remédio são sempre a solução para o seu problema. Isso ficou ilustrado nos discursos a seguir:

Porque faz 15 dias e eu não tomo nada, não é? Vim doente, mandaram eu procurar o 
hematologista, ficam de conversa... E até agora não estou tomando nada [...]. (E4).

É tanto médico que eu não sei..., mas a minha médica era A., primeiro era A., ai mudou para um médico por causa do problema de tireoide, ai eu fui pro médico de tireoide [...]. (E3).

Houve discursos que deixaram transparecer a dificuldade de os pacientes identificarem seus médicos dentro da equipe:

Tem um 'bocado' de residente, sabe...? Ai ninguém sabe qual é o que fica [...]. (E3).

É porque eu não sei nem quem é, porque são muitos médicos [...]. (E7).
Não conheço ninguém, não. Não conheço. Chega um, chega outro que eu não sei... Não conheço ninguém. (E2).

É porque eu nem sei quem é, porque são muitos médicos! [...]. (E7).

Pelo método de nuvem de palavras, que agrupa as palavras e as organiza graficamente em função da sua frequência, verificou-se que se identificam as palavras "médico" e "porque" como destaque, seguidas por outros vocábulos como "estou", "muito" e "disse". Estas palavras que obtiveram frequências mais altas apareceram $71,69,63,52$ e 40 vezes, respectivamente, na transcrição do corpus textual (Figura 1).

Figura 1 - Nuvem de palavras criada pelo NVivo a partir das respostas dos entrevistados.

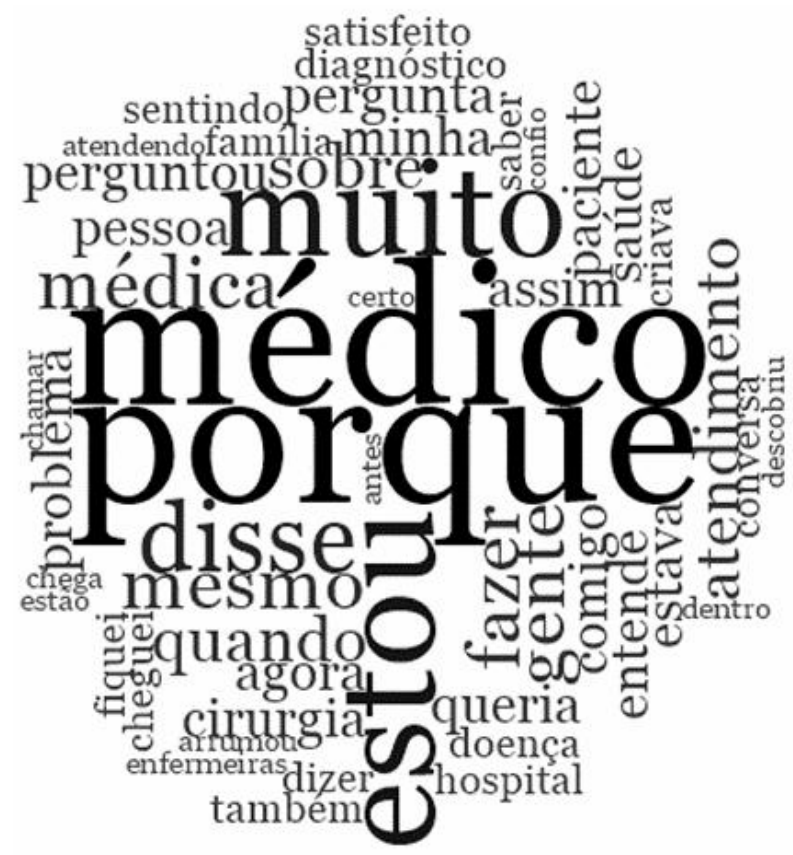

Fonte: Autores (2019)

Nota: ilustração organizada através do software NVivo.

\section{Discussão}

As principais necessidades dos pacientes hospitalizados são confiança, comunicação, informação, educação, autocuidado e apoio.(23) Contudo, para que tenham essas necessidades atendidas, a atenção clínica deve ser centrada neles. Ao longo do último meio século, as abordagens paternalistas e focadas na doença passaram a ser fortemente criticadas. Há uma literatura crescente sobre medicina centrada no paciente, ${ }^{(3,24)}$ medicina centrada na pessoa, ${ }^{(25-26)}$ método clínico centrado na pessoa, ${ }^{(11,25)}$ abordagem centrada na pessoa $^{(27)}$ e cuidado centrado na pessoa, ${ }^{(28)}$ para enfatizar o cuidado a seres humanos completos, trabalhando respeitosamente com preferências, necessidades 
e valores individuais. ${ }^{(29)}$ Mesmo que os termos "paciente", "cliente", "usuário" e "pessoa" sejam frequentemente usados de forma intercambiável na literatura, ${ }^{(30)}$ a ideia de atender a pessoa por trás do paciente abriu o caminho para intervenções em termos de capacitar e encorajar os doentes a trazer seus conhecimentos, preferências e valores para a tomada de decisões e planejamento de cuidados. Deste modo, "centrado na pessoa" é a expressão reconhecida como mais adequada. ${ }^{(30)}$ Foi um psiquiatra inglês de origem húngara, que cunhou o termo "medicina centrada no paciente" $(1970),{ }^{(31)}$ para contrastar com "medicina centrada na doença", com diversos autores contribuindo desde então para construção deste conceito de abordagem.

A baixa escolaridade dos pacientes da nossa amostra é compatível com os resultados de estudos em que se analisou o perfil de indivíduos que procuraram os serviços hospitalares públicos no Brasil. ${ }^{(32-33)}$ Pesquisa realizada em todo território brasileiro revelou que, para os usuários do Sistema Único de Saúde (SUS), há predominância da baixa escolaridade e de não-empregados. ${ }^{(33)}$ Assim, considerando que o grau de escolaridade reflete no senso crítico e que a maioria das pessoas entrevistadas não era alfabetizada ou possuía o ensino fundamental incompleto, a expectativa dessas pessoas em relação ao atendimento médico pode ser menor. Em populações carentes, o acesso limitado dos pacientes a informações de saúde pode dificultar sua capacidade de obter cuidados e compreender as complexidades que regem a prestação de cuidados de saúde, incluindo sua relação com a equipe de saúde.

Em estudo realizado em um hospital universitário de São Paulo - SP, ${ }^{(34)}$ observou-se que 96\% de 126 pacientes entrevistados consideraram bom o atendimento médico recebido. Cogitase a questão da satisfação porque se trata de um atributo relacionado à relação do paciente com a equipe de saúde, e cujo principal componente é a comunicação, em que o profissional compreende e esclarece o diagnóstico e o plano terapêutico ao doente. ${ }^{(35)}$ Em estudo realizado nas mesmas enfermarias onde foram selecionados os pacientes do presente estudo, observou-se que os participantes ficaram satisfeitos com a assistência hospitalar, a equipe médica e de enfermagem, assim como com o resultado do tratamento e as condições físicas do hospital, porém poucos relataram obtenção de informações sobre sua doença e tratamento pela equipe de saúde. ${ }^{36)}$

Há outros fatores envolvidos nesta relação entre satisfação do paciente e escolaridade. Teorias desenvolvidas para explicar os determinantes psicossociais de variáveis relacionadas ao contentamento do enfermo e que definem a questão da satisfatoriedade como um equilíbrio entre as expectativas com o atendimento e a real prestação deste, ${ }^{(37)}$ pois se supõe que a satisfação depende da diferença percebida entre a expectativa do indivíduo e o que efetivamente ele recebe, considerando sua familiaridade, por experiência própria, com potenciais deficiências no sistema de prestação de cuidados de saúde. ${ }^{(38)}$ A satisfação do paciente está associada à quantidade de informação recebida, à comunicação social, à competência técnica e interpessoal, aspectos que fortalecem a confiança que o sujeito credita ao médico. ${ }^{(39)} \mathrm{Um}$ fator que interfere são os patamares diferenciados ocupados pelo médico e pelo enfermo, o que dificulta o estabelecimento de um encontro positivo e favorece uma construção vertical e hierárquica. Há que se destacar que este estudo foi realizado em um hospital universitário, nível terciário de atenção à saúde, entendido como um conjunto de procedimentos que, no contexto do Sistema Único de Saúde, envolve alta tecnologia e alto custo, objetivando proporcionar à população o acesso a serviços qualificados, integrando-os aos demais níveis de atenção à saúde. ${ }^{(40)}$

Nesse sentido, hospitais-escola, além de agregar esses desafios, têm como característica incorporar a função de hospital à missão de formação e treinamento de profissionais da saúde. É desejável que estas instituições sejam referência para a assistência e também formadoras de recursos humanos para o SUS, portanto, devem primar por um padrão de excelência de cuidados à saúde. Em face desses desafios, as organizações hospitalares 
têm buscado a superação do modelo médicocentrado e hierarquizado historicamente construído e ainda predominante. ${ }^{(41)}$ Ainda segundo a mesma autora, atualmente, as instituições hospitalares são sistemas abertos que sofrem a ação do meio, sendo influenciadas pela evolução e mudanças em todos os campos sociais, tornando-se um espaço multidisciplinar de interação com a sociedade. Nesse sentido, os hospitais atuais contêm um sistema mais humano do que mecânico, mas com regras para controlar o comportamento e o trabalho de seus membros. Assim, vêm perdendo suas características paternalistas e autoritárias, assumindo caráter de organização funcionalracional-burocrática. ${ }^{(42)}$

Por outro lado, desde 2001, os profissionais da saúde brasileiros passaram a ser formados de acordo com orientações políticas voltadas para práticas mais humanizadas, capacitados para atuar, com senso de responsabilidade social e compromisso com a cidadania, como promotores da saúde integral do ser humano. Especificamente, dentro da medicina, o Brasil tem vivido um período de revisão de currículos médicos, a partir da discussão e publicação das Diretrizes Curriculares Nacionais $(\mathrm{DCN}){ }^{(15)}$ embora a medicina centrada na pessoa, ainda que valorizada, não é abordada explicitamente de forma ampla nas escolas médicas ou durante os programas de residência. ${ }^{(43)}$ No entanto, a introdução de modelos inovadores de cuidados de saúde não significa necessariamente que sejam incorporados prontamente na prática clínica diária de forma integral.

Dentre os resultados obtidos com as perguntas da entrevista, a maioria dos entrevistados encontrava-se satisfeita com as informações que recebeu do médico a respeito do seu diagnóstico, da sua condição como um todo, enquanto 90,9\% dos indivíduos percebiam seu principal médico como capaz/competente. $\mathrm{Na}$ análise das narrativas obteve-se a associação de diversos discursos a unidades temáticas que se enquadram dentro do método clínico centrado na pessoa, em contrapartida obtiveram-se também discursos que não se enquadram nesse modelo, os quais foram agrupados sob uma categoria separada. Dessa forma, os discursos foram classificados sob as seguintes categorias: (1) Exploração da doença e a experiência da pessoa com a doença; (2) Entendimento da pessoa como um todo; (3) Elaboração de um plano comum de manejo; (4) Fortalecimento da relação médico pessoa; e, por último, a categoria de contraponto: (5) Modelo biomédico. Quando se opõe a atitude centrada no médico à atitude centrada no paciente, o ponto em discussão é o poder do médico versus a autonomia do paciente. Quando a oposição é entre doença e doente, a medicina centrada no paciente é mais abrangente, buscando entender as necessidades e desejos da pessoa e não se restringe à doença. ${ }^{(3)}$ Para abordar o adoecimento deve-se incluir na abordagem do indivíduo a investigação de quatro principais aspectos (que podem ser lembrados com o mnemônico SIFE): a) os sentimentos do paciente diante da doença - tranquilidade, tristeza, raiva, culpa, medo; b) suas ideias em relação ao padecimento - relações causais, explicações místicas; c) as implicações em sua funcionalidade - no trabalho, nas atividades de vida diária; d) e suas expectativas - em relação ao tratamento, evolução, cura e papel do médico. ${ }^{(11)}$

A partir deste ponto será feita a discussão dos resultados dividindo as categorias já apresentadas em subtópicos, para facilitar o detalhamento e a compreensão.

\section{Categoria 1 - Exploração da doença e a experiência da pessoa com a doença}

Na categoria 1, que consiste na abordagem da experiência do adoecimento, significa explorar não só a doença em si que o paciente apresenta no momento, mas tudo o que se refere a ela na sua vida: medos, crenças, pensamentos. $\mathrm{O}$ foco, nesse caso, sairia do corpo única e exclusivamente e seria transferido para a pessoa que passa pela experiência da doença. Os discursos expressam sentimentos de gratidão relacionados à obtenção do diagnóstico do paciente com relação ao médico. Também existe denotada satisfação quando os 
entrevistados falam sobre a forma como são tratados pelos médicos e a abordagem dos seus problemas, particularmente porque parecem vincular o contato do exame físico, assim como a conversa com o médico sobre os sintomas, com a estima que o profissional de saúde parece ter por eles, ou seja, com o quanto o médico se importa com eles. Trabalhos anteriores também mostram que as habilidades interpessoais estão entre as características mais desejadas pelos pacientes nos seus médicos. ${ }^{(44)}$ Dentre essas habilidades interpessoais, a dimensão da comunicação é considerada uma das mais importantes, mas ocorrem problemas desde a coleta da história até o momento da discussão com o paciente sobre a conduta no caso, que podem estar relacionados à falta de habilidade interpessoal, tanto da parte do médico quanto do paciente, provocando prejuízo no diagnóstico e no tratamento. ${ }^{(11)}$

Para esse primeiro componente, é imprescindível diferenciar os termos doença e adoecimento. A doença é uma construção teórica com base em observações objetivas que tentam explicar o problema, enquanto o adoecimento é a experiência pessoal e subjetiva de quem está doente, sendo expressa de modo diferente para cada indivíduo. ${ }^{(45)} \mathrm{A}$ doença e o adoecimento nem sempre coexistem, pois pessoas com doenças assintomáticas nem sempre se sentem doentes, e pessoas deprimidas podem se sentir doentes, mas podem não ter comprometimento orgânico aparente. Escutá-las sobre sua experiência de doença pode ser esclarecedor para o diagnóstico e ajudar na decisão de quais estratégias clínicas serão mais eficazes, mas também faz com que o paciente se sinta ouvido e, assim, estreite a relação médico-pessoa. ${ }^{(25)}$

Assim, é pela narrativa da vivência que se pode ter contato com os sentimentos e significados que ela desperta e, nesse sentido, se aceita que o discurso do sujeito que vive a experiência é que a torna conhecida e a análise desse discurso é a expressão verbal da experiência vivida. Eis porque, na linha que conduziu o estudo, foi no discurso do sujeito que se revelou a percepção dos entrevistados sobre o componente de exploração de seus sinais e sintomas de forma que pareceu a eles estarem sendo entendidos e atendidos em suas expectativas.

\section{Categoria 2 - Entendimento da pessoa como um todo}

O segundo componente, que consiste em entender a pessoa por inteiro, pode ser divido em duas partes: entender o indivíduo singularmente e sua relação com a família, assim como entender o contexto no qual vive esse paciente (trabalho, relações sociais, fatores culturais etc.), ou seja, o contexto de vida e pertencimento da pessoa emergem, indicando que as relações familiares e sociais envolvem, ou estão sendo afetadas, pelo adoecer. $^{(25)}$ Nos discursos obtidos foi demonstrada uma interação no sentido de compreender o ambiente em que vivia o paciente. Com alguns dos entrevistados, o médico parece ter conseguido um contato próximo ao ponto de estabelecer comunicação por telefone, antes da internação atual, para saber da melhora deles e marcar um retorno ao serviço diante de uma possível piora. Com outros, foi possível obter abertura a respeito da estrutura familiar, comportamento, sentimentos a respeito dos detalhes da vida pessoal.

Mas na maioria dos diversos serviços públicos hospitalares de saúde, esse contato próximo não ocorre. Atualmente, são frequentes as reclamações dos usuários quanto ao atendimento hospitalar. É alegada a falta de atenção adequada por parte dos profissionais que atuam em ambiente nosocomial. Por outro lado, os funcionários da saúde insistem em frisar as precárias condições para executarem seus trabalhos. ${ }^{(14)}$ Diante da deterioração da oferta dos serviços de saúde, parece óbvio dizer que tanto os usuários quanto os profissionais de saúde estão corretos em suas reclamações, porém a humanização da assistência hospitalar vai além desses dois polos. Ambos os agentes envolvidos necessitam compreender que o diálogo de qualidade constitui um passo inicial na melhor navegação do sistema, mesmo com 
suas grandes falhas, para ambas as partes. Se de fato a intenção for humanizar o serviço prestado, esse modo autêntico de percepção do outro sinaliza que é possível haver uma assistência singular e compreensiva ao paciente no contexto hospitalar, mesmo nos hospitais públicos, onde a crise de financiamento da saúde é mais evidente. ${ }^{(14)}$ Além disso, emoções como esperança e otimismo estavam presentes nas falas dos respondentes, sugerindo que as expectativas destes foram atendidas, embora os pacientes muitas vezes não expressem explicitamente suas necessidades por causa das pressões de tempo sobre os médicos, o que representa uma barreira organizacional para a comunicação nas enfermarias dos hospitais.

Os médicos lidam com a integração de conhecimentos teóricos aprendidos em instituições acadêmicas com as realidades da prática clínica, muitas vezes porque fatores contextuais como restrições de tempo, acuidade do paciente e aumento da carga de trabalho dificultam sua capacidade de cuidar dos pacientes de forma a trazer satisfação. Por outro lado, os múltiplos aspectos socioculturais e comportamentais envolvidos na questão do atendimento médico têm sido objeto de estudo de diversos ramos das Ciências Sociais e sua aplicação à área da saúde, como é o caso da antropologia médica. Paralelamente ao avanço e sofisticação da biomedicina foi sendo detectada sua impossibilidade de oferecer respostas conclusivas ou satisfatórias para muitos problemas ou, sobretudo, para os componentes psicológicos ou subjetivos que acompanham, em grau maior ou menor. Mesmo que muitos profissionais cheguem a admitir a existência de componentes de ordem subjetiva ou afetiva, que exercem influência mesmo em casos de doenças em que as evidências orgânicas sejam mais explícitas, não se sentem, com frequência, à vontade para lidar com eles. ${ }^{(14)}$

O modelo biomédico hegemônico estimula os médicos a aderirem a um comportamento cartesiano na separação entre o observador e o objeto observado. Proclama-se a necessidade de um "distanciamento objetivo", visto como uma qualidade que cabe preservar ou mesmo incrementar, por mais que seja inerente ao ato médico uma interação significativa e mais ou menos intensa entre médico e paciente, e que essa interação seja fundamental para o sucesso terapêutico. A intensificação da divisão do indivíduo em partes contribui sobremaneira para dificultar a valorização do todo. Até mesmo quando a comunicação se restringe ao âmbito terminológico, os médicos têm dificuldades em descrever o todo, a não ser por meio das partes. Desta maneira, por mais que alguns profissionais queiram visualizar seu paciente como um todo e situá-lo, de alguma maneira, no seu contexto socioeconômico, terminam por regressar ao reducionismo mecanicista, pois esse foi o modelo em que foi pautada sua formação na escola médica. ${ }^{(46)}$

Entretanto, é necessário considerar que este estudo fez uso do discurso do paciente como meio principal de obtenção das informações e da sua capacidade de revelar a vivência e a história de cada um com a figura do médico durante a internação hospitalar, mas há que considerar também o aspecto contextual que não favorece melhor interação. Nesta inter-relação, é fundamental considerar três pontos: o primeiro ponto está relacionado ao cenário em que as ações se passam, ou seja, um cenário regido por normas e rotinas, as quais por si só, constituem uma forma de pressão sobre a fala dos entrevistados, inseridos no contexto clínico como "pacientes"; o segundo ponto está associado ao sujeito e ao significado que ele atribui à relação com a figura do médico; e o terceiro ponto referese à leitura e interpretação que este sujeito faz da postura ou das ações empregadas pelo outro, o médico, na dinâmica da relação.

Categoria 3 - Elaboração de um plano comum de manejo

Esse terceiro componente do MCCP propõe que médico e paciente encontrem um terreno comum, ou seja, entrem em acordo com a agenda e as prioridades do atendimento, as metas do cuidado, para elaborar um plano conjunto de manejo dos problemas, identificando nele os 
papéis assumidos por ambos. ${ }^{(25)}$ Descrições de como os informantes tomaram suas próprias decisões não foram observadas nas respostas dos entrevistados, embora alguns estivessem cientes do que estava acontecendo durante a hospitalização. Determinados pacientes não descreveram uma necessidade não atendida, relacionada com o conhecimento indispensável e, nesse sentido, não poderiam ser capazes de escolher entre procedimentos e tratamentos. Isso torna difícil o surgimento de narrativas sobre oportunidade de escolher, pois não tinham conhecimento suficiente para fazer escolhas, nem parece ter havido essa postura de informar por parte dos médicos. Nesse sentido, vale destacar que por não estarem acostumados com esse tipo de conversa mais subjetiva, em que seus sentimentos são abordados de forma explícita, os entrevistados podem não ter demonstrado assim, o que realmente sentiam.

Embora nos discursos analisados não se tenha observado a efetivação de um compartilhamento de decisões com os pacientes, houve falas com informações que estes parecem ter compreendido a opção terapêutica e aceitaram passar pelos procedimentos. Contudo, a escolha da melhor opção de tratamento disponível deve levar em conta as preferências do paciente, único capaz de tornálo efetivo. ${ }^{(11)} \mathrm{O}$ fornecimento de informações sobre as opções de cuidados, os benefícios e malefícios de cada opção, os resultados relevantes esperados e posteriormente ouvir a opinião do paciente sobre o que foi exposto constitui uma estratégia para a tomada de decisão compartilhada, o que não foi explicitado nas respostas dos entrevistados. O respeito ao medo e às crenças do paciente se torna, nesse momento, fundamental.

O enfermo revela gratidão pela cordialidade do profissional de saúde e pela obtenção do diagnóstico, além de demonstrar uma atitude positiva a respeito do seu prognóstico. Estudos mostram uma série de desfechos positivos provenientes de uma comunicação adequada durante a discussão do plano de manejo, pois informações claras, juntamente com apoio emocional, são capazes de influenciar positivamente a evolução clínica. ${ }^{(47)}$ Os pacientes precisam encontrar interpretações aceitáveis do que está acontecendo com eles, o que é essencial para a sua participação. Quando diferentes membros da equipe (residentes, médicos assistentes, graduandos de Medicina) parecem fornecer informações, o paciente pode se sentir confuso, como foi observado em recortes de falas agrupadas em outras categorias. Consequentemente, a informação precisa ser adequada, ajustada individualmente, coordenada e unívoca.

Mesmo quando o discurso médico ultrapassa os aspectos biológicos e avança em direção aos fatores psíquicos e sociais do processo saúdedoença, estes, quase sempre, orbitam ao redor da doença. A medicina dá uma configuração concreta à sua prática, constituindo um "sujeitoda-doença". ${ }^{(48)}$ Esta expressão "sujeito-da-doença" reflete, segundo a referida autora, o exercício de um poder sobre o corpo do doente. Nesta perspectiva, é para a doença que o saber médico se dirige, e não para o indivíduo. Ainda de acordo com essa perspectiva, o paciente compartilha da "crença" dos médicos, que exigem simplesmente a obediência aos seus preceitos, levando o indivíduo a se colocar sob sua tutela. ${ }^{(48)}$

Vários respondentes expressaram sentimento de frustração por não entender o diagnóstico dado em termos técnicos. Tal discurso pode ser considerado como a expressão da necessidade de serem envolvidos, para estar no comando e expressar seus desejos pessoais. Deixando a responsabilidade pela própria saúde, os informantes descreveram que às vezes eles querem que os médicos decidam qual ação adicional tomar, porque percebem que não têm o suficiente conhecimento, mesmo que tenham recebido informação. Assim, eles colocam no médico a responsabilidade de tomar decisões competentes, e um dos pacientes expressou ser a responsabilidade do médico inferior apenas à ação divina, afirmando que não teriam o que fazer se não confiassem no médico. Essa relação caracteriza o que é conhecido como uma postura paternalista do médico na relação com o paciente, que não é compatível com o modelo clínico centrado na 
pessoa. A chamada "expectativa cerimonial" promove a identificação no médico da imagem de possuidor de poderes excepcionais (saber científico e autoridade profissional) que remetem o paciente a um imaginário cultural oriundo da imagem mítica da arte de curar. ${ }^{(49)}$

O desejo expresso pelos pacientes de recuperar a saúde e suas esperanças de receberem diagnóstico e tratamento está de acordo com a "competência médico-técnica", reconhecida pelos próprios enfermos como a dimensão necessária para a qualidade de seu atendimento. Geralmente no cotidiano hospitalar, o paciente acata todas as orientações recebidas do médico, sem questionar ou reivindicar possíveis alterações em vista desse entendimento. $\mathrm{Na}$ verdade, na maioria das vezes, os doentes hospitalizados nem entendem todos os procedimentos e condutas que estão sendo tomados com ele e o seu próprio corpo, porém não questionam a respeito, ${ }^{(50)}$ como foi observado no presente estudo.

No complexo hospitalar, mudanças nessa postura parecem ser mais lentas, pois o paciente sente-se desprotegido e impotente em um ambiente com tantas especificidades, onde sua integridade é frequentemente rompida - física, emocional e socialmente - por exames, procedimentos e rotinas, invasivos ou não. Por outro lado, culturalmente, as condutas médicas neste tipo de serviço costumam ser mais valorizadas que as dos demais profissionais da equipe. Embora a participação do paciente seja claramente importante, o habitual processo de visitas à beira do leito hospitalar raramente o encoraja, enquanto diretrizes gerais e protocolos estão disponíveis para apoiar tomadas de decisão centrados na doença e no médico, não havendo ferramentas disponíveis para orientar sistematicamente a participação do paciente. ${ }^{(51)}$ Neste cenário, a relação entre médico e paciente se consolida como uma relação de poder, ao exibir uma concepção histórica da institucionalização. ${ }^{(17,50)}$

Com a predominância dessa postura, os pacientes deixam de ser fortalecidos, e se tornam menos proativos e autônomos em participar de atividades de autocuidado. $\mathrm{O}$ empoderamento do paciente é considerado uma forma viável de promover o autocuidado, e a melhor abordagem para o gerenciamento da terapêutica. Assim, nesta conjuntura, considerando-se os profissionais de saúde como especialistas e os enfermos como sujeitos que trazem pouco ao hospital, além de sua doença, inexiste uma parceria no compartilhamento das decisões. ${ }^{(51)}$ Uma vez que o sucesso de uma possível parceria requer habilidades interpessoais e de comunicação por parte dos profissionais de saúde, ${ }^{(17)}$ a falta da percepção por parte do paciente de uma atitude negativa dos médicos quanto a uma comunicação inadequada passa a ser um comportamento que tende a se repetir e ser considerado natural, perpetuando-se na prática clínica.

\section{Categoria 4 - Fortalecimento da relação médico-pessoa}

O quarto componente, talvez o mais subjetivo de todos, requer que o médico empregue a alteridade para se aproximar e cultivar uma relação com seu paciente que vá além do diagnóstico e da prescrição de medicamentos. Esse componente depende do envolvimento do médico com a experiência do adoecimento e com o ciclo de vida do paciente. Neste quarto componente, é ressaltada a importância de se fortalecer a relação médico-pessoa/paciente-pessoa, um processo que deve ser construído durante todo o atendimento e ser aprimorado em todas as visitas em uma assistência longitudinal. ${ }^{(11)}$ Essa relação, considerados os fenômenos de transferência e contratransferência, deve ser sustentada pelos conceitos de empatia e compaixão, e que foram observados pelos pacientes nos comportamentos dos seus médicos. Tais percepções dos entrevistados podem ser consideradas como fenômeno de contratransferência, porém não se observaram narrativas que sugerissem o fenômeno da transferência, por parte dos pacientes, além dos aspectos mencionados anteriormente, relacionados à gratidão e ao reconhecimento do desvelo observado por eles nas atitudes dos médicos. 
Este é outro aspecto a ser considerado, pois o adoecimento leva os pacientes a um estado de regressão para situações vivenciadas anteriormente ao longo da vida, sobretudo referentes aos relacionamentos interpessoais. Em virtude da importância da figura do médico para os pacientes, observaram-se falas em que eles parecem transferir para o profissional as expectativas boas de relacionamentos vivenciados antes. Por outro lado, os pacientes podem não ter condições de relatar fielmente sua percepção sobre o médico, pois seu estado emocional os impede e tendem a não se expor, afirmando o que realmente pensam, por causa de sua situação de dependência ou por frustrações precedentes na comunicação "pacientemédico", o que poderia representar também um evento compatível com a contratransferência.

Alguns dos discursos encontrados revelam uma postura compassiva do profissional de saúde, em que ele se preocupou em transmitir confiança ao paciente sobre sua condição e tentou buscar o melhor uso possível dos recursos para atendê-lo. Nesses casos, pode-se perceber que quando a relação médico-paciente é construída adequadamente, torna-se capaz de gerar reações emocionais importantes que podem chegar a modificar o curso do adoecimento. Integra-se a essa visão da boa relação com o médico, o vínculo anterior de confiança com a própria instituição, adquiridos por significação social e pessoal, onde a relação com o hospital e com os demais profissionais parece confundir-se, como mostram dois dos discursos dos entrevistados. Nesse sentido, os pacientes ressaltaram que o cuidado, para além de uma ação técnica, envolve uma relação afetiva. É importante destacar que os entrevistados atribuíram ao hospital universitário a excelência em qualidade no cuidado, e comparando a outras instituições, especialmente públicas, reconheceram estar sendo bem cuidados. Este cuidado, mediante as declarações, é verificado, sobretudo, pela presença da equipe médica e dos demais profissionais de saúde nas enfermarias. Essa presença incluiu ainda a visita dos alunos, por se tratar de um hospital universitário, aumentando a sensação dos doentes de estarem sendo realmente cuidados, como um dos respondentes referiu, ao ser internado em outras instituições às quais relacionam um cuidado precário em comparação ao hospital universitário, lócus da pesquisa.

Os pacientes relataram a relação com o médico como "boa", percebendo os profissionais como atentos, responsáveis e dedicados. Os respondentes associam a boa relação ao cuidado recebido mediante a realização de exames clínicos realizados, tratamentos e procedimentos propostos, resultado semelhante ao que foi observado em estudo anterior. ${ }^{(52)}$ A presença do profissional novamente é colocada como um ponto positivo na relação, além de outros aspectos afetivos como encorajamento para o cumprimento da terapêutica proposta, o enfrentamento da hospitalização, a visitação diária e o acesso por contato telefônico para comunicação de piora clínica posterior à alta, como foi mencionado por um dos doentes.

Os comentários mais citados pelos pacientes como sendo críticos para suas experiências em relação à figura do médico foram de que este os ouvia, era atencioso e compassivo, embora nem todos concordassem que havia um médico que explicasse bem o que apresentavam. A maioria deles comentou sobre a importância de um médico que ouve, cuida e explica as questões aos pacientes. Vários estudos mostraram que, ao se referirem aos seus médicos, os pacientes raramente mencionam conhecimentos técnicos, mas concentram-se na empatia e capacidade de fornecer explicações claras. ${ }^{(53)}$ Contudo, os resultados da maioria das pesquisas de avaliação dos serviços de saúde pelos usuários têm sido positivos, o que não quer dizer necessariamente que o serviço seja bom, podendo expressar ausência de opinião, ausência de avaliação crítica e a "aceitação do paternalismo médico". ${ }^{(54)}$

O fato de o local da pesquisa ser um hospitalescola e ter a presença constante de várias pessoas no cuidado - professores, profissionais efetivos do local, graduandos, residentes e estagiários parece confirmar a importância da presença multiprofissional no cuidado, da proximidade, do 
toque, do ouvir e ser ouvido, do contato efetivo entre pessoas para confortar, tanto por meio das questões técnicas, quanto afetivas. Os pacientes louvaram a parte técnica e procedimental do cuidado por parte dos médicos, o que corrobora estudo anterior. ${ }^{(52)}$ Todos os pacientes da clínica das enfermarias do HULW recebiam cuidados de médicos residentes em programa de treinamento de clínica médica e outras especialidades de medicina interna, usando o modelo tradicional de um rodízio de continuidade mensal de acompanhamento para cada médico residente pelas enfermarias. Apesar da descontinuidade, os residentes podem influenciar positivamente a qualidade dos cuidados e os resultados, desenvolvendo relações interpessoais próximas com os pacientes, como algumas falas demonstraram.

Ao mesmo tempo em que, como foi destacado, os pacientes geralmente experimentam um novo conjunto de médicos residentes à medida que a internação prossegue, com pouca continuidade dos cuidados, eles muitas vezes se sentem confusos diante do número de membros da equipe de saúde nesse tipo de instituição hospitalar, marcada pela presença de vários deles durante sua permanência no hospital. ${ }^{(55)} \mathrm{O}$ MCCP parece ser pouco explorado dentro dos muros dos hospitais, mesmo nos hospitais-escola, e nestes, a sistemática do cuidado privilegia os interesses do programa de treinamento em serviço, para que os residentes acompanhem um maior número de pacientes na sua pós-graduação.

\section{Categoria 5 - Modelo biomédico (de saúde)}

$\mathrm{Na}$ expressão dos pacientes, o modelo biomédico foi exibido mediante a hipervalorizarão de exames complementares, através da concepção de que pedir mais destes era uma forma de o médico demonstrar que se importava com eles. A medicação era, por vezes, vista como solução para todos os problemas, mas a compreensão dos entrevistados sobre o processo saúde-doença pareceu limitada pela utilização de uma linguagem inacessível ou falta de uma explanação mais clara sobre o seu problema de saúde, aspectos compatíveis com o modelo biomédico de atenção.

Alguns pacientes deixaram transparecer a sensação de fragilidade diante do adoecimento e da hospitalização prolongada, expressando ansiedade e se perguntando por que ainda permaneciam hospitalizados. Houve fragmentos de discursos em que eles pareceram não entender sua permanência e não aceitar a hospitalização, considerando-se nessas falas importante o desconhecimento de quem seria realmente o seu médico diante do número de figuras que representavam esse profissional. Nesta classe, o discurso dos pacientes, se explicita, ao contrário das falas descritas em outras categorias, certa insubmissão aos procedimentos e à hospitalização. Resultados semelhantes são apontados em outra pesquisa, quanto às atitudes dos hospitalizados. Segundo as pesquisadoras referidas nesta última citação, os pacientes questionam sua permanência prolongada, ao mesmo tempo em que são mais passivos na responsabilização de decidir quanto ao tratamento, delegando aos médicos as escolhas, como mencionado anteriormente em relação ao componente 3 do MCCP. ${ }^{(52)}$

$\mathrm{O}$ modelo biomédico geralmente explica o processo saúde-doença de uma forma unicausal, pressupondo o reconhecimento de um agente etiológico que deverá ser reconhecido e combatido. Em torno desse aspecto tem-se o biologicismo (reducionismo que enfoca a existência apenas de um agente biológico que provoca a doença), fragmentação (o corpo humano fragmentado em diversas partes que são cuidadas separadamente), mecanicismo (o corpo humano é enxergado com uma máquina imperfeita que deve ser investigada e revisada buscando erros em seus processos), hospitalocentrismo (centralização do cuidado nos hospitais), tecnicismo (ênfase nos procedimentos técnicos) e a especialização (visão focada mais nas partes do que no todo do paciente), ${ }^{(56)}$ aspectos que podem explicar as reações contrárias desses respondentes.

Essas características, compatíveis com o modelo biomédico, são preponderantes nos atendimentos hospitalares. O hospital é uma unidade 
na qual se reúnem profissionais, conhecimento, tecnologia e estrutura para se produzirem cuidados aos pacientes, seguindo uma perspectiva tradicional baseada no desenvolvimento científico e técnico da medicina no controle de doenças até o limite da cura. ${ }^{(12)}$ Os discursos encontrados nesta pesquisa revelam relativa concordância com essas características, considerando os fragmentos de discursos em consonância com este modelo centrado na doença.

Dois estudiosos europeus influenciados pela psicanálise e pela filosofia, propuseram três modelos conceituais de relação médico-paciente: No tipo de relação chamada de "atividadepassividade", o paciente abandona-se por completo e aceita passivamente os cuidados médicos, sem mostrar necessidade ou vontade de compreendêlos. Na relação de "direção-cooperação", o médico assume seu papel de maneira, até certo ponto, autoritária, mas o paciente compreende e aceita tal atitude, procurando colaborar. No tipo de relação de "participação mútua", o médico permanece no seu papel de definir os caminhos e os procedimentos, mas o paciente compreende e atua conjuntamente, assumindo a corresponsabilidade. ${ }^{(57)}$ Considerando esses tipos de relação médico-paciente, as narrativas observadas no presente estudo, encontraram-se características dos tipos de relação atividadepassividade e direção-cooperação, porém não há narrativas compatíveis com o terceiro tipo de interação.

Tais modelos de atividade-passividade e de direção-cooperação são consistentes com o modelo paternalista, baseado na tradição hipocrática e que coloca a relação médico-paciente nos termos em que o médico decide que testes ou intervenções são melhores para o paciente. Nesse caso, o médico apresenta ao paciente informação selecionada, que encorajará o consentimento da intervenção considerada a melhor pelo médico. Em modos extremos, o médico meramente avisa o paciente quanto à intervenção que será iniciada, sem considerar a opinião do paciente. ${ }^{(58)}$ Isso não está em consonância com a Carta dos Direitos dos Usuários do Sistema Único de Saúde - SUS, ${ }^{(59)}$ que preconiza que sejam fornecidas informações sobre o seu estado de saúde, extensivas aos seus familiares e/ou acompanhantes, de maneira clara, objetiva, respeitosa, compreensível e adaptada à condição cultural, respeitados os limites éticos por parte da equipe de saúde sobre, entre outras, hipóteses diagnósticas, diagnósticos confirmados, exames solicitados e terapêuticas propostas. ${ }^{(60)}$

Assim, o maior ou menor grau de integralidade alcançada na atenção disponibilizada segundo as falas dos entrevistados advém do modo como se dá a interface entre as ações dos médicos, à questão do modelo de atenção operacionalizado nos serviços - se médico-centrado ou se usuário-centrado. Um modelo usuário-centrado prevê a responsabilização no cuidado a este indivíduo portador de direitos, logo, um serviço responsivo e resolutivo demanda não só o conhecimento técnico-científico, recursos materiais, mas também o acolhimento e vínculo. ${ }^{(12)}$ No MCCP, um modelo baseado essencialmente na interação entre doente e médico - enquadra-se no tipo de participação mútua, tendo por base a consideração da perspectiva daquele que procura atendimento - suas expectativas, medos, ideias e valores - e a importância de sua participação para o sucesso do tratamento, o oposto ao da medicina centrada na doença (modelo biomédico).

Quando se pensa a respeito dos hospitais universitários, como setor de média e alta complexidade na área da saúde, não raro reportase à ideia de um serviço complexo cuja prática profissional é distante dos moldes de humanização/ integração profissional-usuário. Ainda que culturalmente se pense no hospital como a instituição da doença, há potencialidades do espaço hospitalar como produtor do cuidado, enfocando a educação em saúde como uma possibilidade de efetivação do MCCP, pois todos os níveis de atenção guardam possibilidades de promoção da saúde enquanto qualidade de vida e direito do cidadão. Os hospitais podem vir a ser importantes instituições na garantia da equidade, integralidade da assistência e na defesa da vida desde que as práticas desenvolvidas estejam comprometidas com algo maior, ligadas não apenas à questão biológica-curativista, que são 
de grande relevância, mas, também, com o universo da prevenção e promoção da saúde. ${ }^{(12)}$

Os médicos podem também não ter inserido adequadamente os pacientes nas discussões sobre o plano por causa de limitações de tempo ou percepções sobre os doentes quanto ao nível de compreensão ou capacidade de compreender o plano. Por outro lado, os médicos podem não ter observado a escassa compreensão de seus pacientes quanto ao plano de cuidados. A insuficiência de tempo e a falta de uma sensibilização prévia, desenvolvida durante a graduação do médico e sua educação continuada, também são apontadas como responsáveis pelo fato de o paciente ser pouco informado e consultado sobre os aspectos que interessam à sua própria saúde. ${ }^{(61)}$

Como discutido anteriormente, em hospitais de ensino os pacientes podem ter dificuldade em identificar quem está envolvido no seu atendimento e quais são seus respectivos papéis. Os médicos em formação podem contribuir para este problema através da incapacidade de se apresentar nominalmente aos pacientes. Além destes fatores, alguns pacientes podem ser menos propensos a identificar seu médico por causa de fatores sociais e educacionais. Independentemente da causa, os pacientes que foram incapazes de identificar seus médicos podem ter sido menos informados e não sabiam especificamente a quem dirigir suas perguntas, prejudicando sua capacidade de tomar decisões informadas durante a hospitalização, ${ }^{(62)}$ pois se considera, a partir da literatura a esse respeito, que mais de $90 \%$ dos usuários que procuram um hospital universitário desejam ser informados sobre suas condições de saúde, incluindo eventuais diagnósticos de doenças graves. ${ }^{(63)}$

O hospital é um lugar altamente profissionalizado que reúne uma diversidade de profissionais que possuem formação e socialização profissional diferenciadas, e que ocupam diferentes posições hierárquicas e desiguais espaços na divisão do trabalho. ${ }^{(12)}$ É importante destacar que um dos aspectos mais relevantes da relação médico-paciente em nosso meio é a de classe socioeconômica. O médico tende a adotar comportamentos diferentes, de acordo com a classe social do paciente. A distância social e cultural que o médico estabelece com as classes menos favorecidas dificulta o direito das mesmas à negociação e à participação dos pacientes. Os serviços, por sua vez, organizam-se na perspectiva dos profissionais e da organização da própria instituição, e tendem a não priorizar as necessidades do usuário, impondo normas, legislações, rotinas e práticas, o que resulta da hegemonia do modelo biomédico na assistência. Isto porque este ambiente foi retratado como local de vigilância clínica constante, com práticas que inibem o exercício da autonomia diante da enfermidade. ${ }^{(64)}$ Por esta razão, a pessoa internada, pela posição que ocupa na relação de cuidado, passou a ser chamada de "paciente". Embora na maioria dos hospitais se acredite que existam cuidados centrados no paciente, muitos não o fazem. ${ }^{(65)}$

A análise dos termos mais frequentes por meio do processamento lexical simples da nuvem de palavras foi consonante com os apresentados na análise temática anterior, visto que a palavra central, "médico", foi cercada pela conjunção "porque", de natureza explicativa, que liga pensamentos de modo que explique ou esclareça, além do advérbio "muito", de intensidade, do verbo "estou", autorreferência à primeira pessoa e indicando achar-se em certa condição ou em determinado estado, e o verbo "dizer", discursar usando palavras, expressão de comunicação.

Existem algumas limitações neste estudo. Escolheu-se usar um instrumento de pesquisa validado com base no MCCP, mas com adaptações na criação de um roteiro de entrevista que englobou questões abertas referenciadas pelo objetivo da pesquisa a partir de revisão sobre a história clínica centrada no paciente. ${ }^{(17)}$

Entretanto, se realizou uma análise apriorística, fundamentada no MCCP assim como nas características do modelo biomédico. A técnica de análise de conteúdo foi usada para descrever as experiências dos pacientes com o atendimento em relação à sua percepção com a figura do 
médico pelo fato de esta técnica de abordagem qualitativa refletir melhor os aspectos relacionados à comunicação humana, aspecto fundamental do MCCP. Nesse sentido a baixa escolaridade da maioria dos entrevistados foi uma limitação, mas foi feito um esclarecimento de perguntas para evitar mal-entendidos e o entrevistador tentou ser sensível ao possível desconforto que os informantes poderiam sentir. Os autores estavam cientes de que a análise poderia ser influenciada pelo modelo de qualidade de cuidados ${ }^{(66)}$ e a influência de aspectos ligados ao contexto hospitalar público sobre a satisfação do paciente, ${ }^{(67)}$ pois há evidências de que a percepção dos pacientes sobre a qualidade dos serviços de saúde depende de 30 a $40 \%$ da capacidade de diagnóstico e terapêutica do médico e de 40 a $50 \%$ da relação que esse estabelece com seu paciente. ${ }^{(68)}$

Uma limitação adicional do estudo foi o fato de não ter sido possível determinar, a partir das entrevistas, se a falta de participação dos pacientes na elaboração de um plano terapêutico comum estava relacionada ao fato de não ser convidado a participar pelo médico ou por não quererem ou não saberem como fazer isso, eles mesmos, no sentido de se envolverem nas decisões sobre seu processo de saúde-doença. Diante disso, é importante a realização de pesquisas que visem compreender e refletir sobre a percepção dos pacientes acerca das práticas médicas, de forma a melhor orientar a educação na saúde e a relação médico-paciente durante a hospitalização.

\section{Conclusões}

A análise das falas dos entrevistados mostra que grande parte se sentiu bem atendida e que suas próprias percepções da situação da enfermidade parecem ter sido respeitadas pelos médicos. Isso foi compreendido positivamente e revelou-se na confiança e satisfação observadas nos discursos, havendo alocuções compatíveis com o MCCP. Contudo, não houve narrativas compatíveis com sua participação ativa nas decisões tomadas, observando-se assim, nesse aspecto, uma relação centrada no médico e/ou na doença, ao lhe conferir posição de autoridade e poder. $\mathrm{Na}$ expressão dos pacientes, elementos do modelo biomédico foram exibidos através da hipervalorizarão de exames complementares, mas combinada à percepção de que realizar mais destes era uma forma de o médico se importar com eles. De forma recorrente, observou-se que os pacientes não identificavam quem era seu médico principal, embora a maioria tenha referido afirmativamente que sabia identificálo, além da menção à utilização de uma linguagem inacessível ou falta de uma explanação mais clara sobre o seu problema de saúde.

Há um longo caminho a ser percorrido na busca de um atendimento mais integralizado aos doentes no que se refere ao MCCP nos hospitais, mesmo nas instituições de ensino, embora tenham ocorrido reformas curriculares recentes e a instituição de programas de humanização hospitalar. A responsabilização conjunta quando à tomada de decisão é um dos fatores essenciais que devem ser estimulados na educação médica no contexto hospitalar, com o objetivo de ofertar a melhor atenção de acordo com as necessidades do doente.

\section{Referências}

1 Oliveira JF, Albertin AL. Uma análise na relação médico-paciente frente aos recursos das tecnologias da informação. Rev Adm Inovação. 2014;11(2): 132-53.

2 Koifman L. O modelo biomédico e a reformulação do currículo médico da Universidade Federal Fluminense. Hist Cienc Saúde. 2001; 8(1): 49-69.

3 Ribeiro MMF, Amaral CFS. Medicina centrada no paciente e ensino médico: a importância do cuidado com a pessoa e o poder médico. Rev Bras Educ Med. 2008;29(1): 90-7.

4 Daaleman TP, Shea CM, Halladay J, Reed D. A method to determine the impact of patientcentered care interventions in primary care. Patient Educ Couns. 2014;97(3): 327-31. 
5 Mezzich JE, Salloum IM. Person centered medicine: core and diversity. Int J Pers Cent Med. 2015;5(4):159-63.

6 Alharbi TS, Carlström E, Ekman I, Jarneborn A, Olsson LE. Experiences of person-centred care - patients' perceptions: qualitative study. BMC Nurs. 2014;13: 28.

7 Stewart M, Brown J, Levenstein J. The patient-centred clinical method III. Changes in residents' performance over two months of training. Fam Pract. 1986;3: 164-7.

8 Stewart MA, Brown JB, Weston WW, McWhinney IR, McWilliam CL, Freeman TR. Patient-centered medicine: transforming the clinical method. Thousand Oaks, CA: Sage Publications Inc; 1995.

9 Stewart M. Reflections on the doctor-patient relationship: from evidence and experience. $\mathrm{Br}$ J Gen Pract. 2005;55(519): 793-801.

10 Stewart M, Brown JB, Donner A, McWhinney IR, Oates J, Weston WW, Jordan J. The impact of patient-centered care on outcomes. J Fam Pract. 2000;49(9): 796-804.

11 Stewart M, Brown JB, Weston WW, McWhinney IR, McWilliam CL, Freeman TR. Medicina centrada na pessoa: transformando o método clínico. 3a ed. Porto Alegre: Artmed; 2017.

12 Guedes HHS, Castro MMC. Atenção hospitalar: um espaço produtor do cuidado integral em saúde. Serv Soc Rev. 2009;12(1): 4-26.

13 Imanishi HA, Silva LL. Despersonalização nos hospitais: o estádio do espelho como operador teórico. Rev SBPH. 2016; 19 (1): 41-56.

14 Ribeiro I, Silveira MGCC. Humanização hospitalar no Sistema Único de Saúde. Rev Interd Ciên Saúde. 2015;2(3): 19-24.

15 Ministério da Saúde (BR). Programa Nacional de Humanização da Assistência Hospitalar. Brasília: Ministério da Saúde; 2001 [citado 2019 fev 26]. Disponível em: http://bvsms. saude.gov.br/bvs/publicacoes/pnhah01.pdf
16 Fontanella BJB, Ricas J, Turato ER. Amostragem por saturação em pesquisas qualitativas em saúde: contribuições teóricas. Cad Saúde Pública. 2008; 24(1): 17-27.

17 França BCC, Soares TF, Toledo AC Jr, Souza NM, Faria RMD. Validação de instrumento de registro do atendimento clínico centrado na pessoa. Rev Bras Educ Med. 2015; 39 (2): 233-9.

18 Baptista MKS, Santos RM, Duarte SJH, Comassetto I, Trezza MCSF. O paciente e as relações de poder-saber cuidar dos profissionais de enfermagem. Esc Anna Nery. 2017;21(4): e20170064.

19 Minayo MCS, organizador. Pesquisa social: teoria, método e criatividade. 18a ed. Petrópolis: Vozes; 2001.

20 Bardin L. Análise de conteúdo. 70a ed. Lisboa: Presses Universitaires de France, 1977.

21 Minayo MCS. O desafio do conhecimento: pesquisa qualitativa em saúde. 8 a ed. Rio de Janeiro: Hucitec/Abrasco; 2004.

22 Fertonani HP, Pires DEP, Biff D, Scherer MDA. The health care model: concepts and challenges for primary health care in Brazil. Ciên Saúde Colet. 2015;20(6): 1869-78.

23 Polikandrioti M, Ntokou M. Needs of hospitalized patients. Health Sci. J.2011;5(1): 15-22.

24 Pires, P. Medicina centrada no paciente: melhor qualidade com menores custos. Rev Port Clin Geral [Internet], 2011 set [citado 2018 dez 6];27(5): 482-6. Disponível em: http:// www.scielo.mec.pt/scielo.php?script $=$ sci arttext\&pid=S087 0-71032011000500012

25 Barbosa MS, Ribeiro MMF. O método clínico centrado na pessoa na formação médica como ferramenta de promoção de saúde. Rev Med Minas Gerais. 2016;26 Sup1 8: S216-S222.

26 Fernandes MG. A medicina centrada na pessoa: o componente espiritual na abordagem pelo Médico de Família e Comunidade [Dissertação]. Rio de Janeiro: Escola Nacional de Saúde Pública Sergio Arouca; 2015. 85 p. 
27 Lopes JMC. A pessoa como centro do cuidado: a abordagem centrada na pessoa no processo de produção do cuidado médico em Serviço de Atenção Primária à Saúde [Dissertação]. Porto Alegre: Universidade Federal do Rio Grande do Sul, Faculdade de Educação; 2005. 223 p.

28 Chibante CLP, Santo FHE, Santos TD, Porto IS, Daher DV, Brito WAP. Saberes e práticas no cuidado centrado na pessoa com feridas. Esc. Anna Nery [Internet]. 2017 [citado 2019 mar 4];21( 2 ): e20170036. Disponível em: http:// www.scielo.br/scielo.php?script=sci_arttext\& pid $=$ S141481452017000200208\&lng=en

29 Mezzich JE, Appleyard J, Botbol M, Salloum MD, Kirisci L. Conceptualization and metrics in person centered medicine. Int J Pers Cent Med. 2016;6(4): 213-8.

30 Naldemirci Ö, Wolf A, Elam M, Lydah D, Moore L, Britten N. Deliberate and emergent strategies for implementing person-centred care: a qualitative interview study with researchers, professionals and patients. BMC Health Serv Res. 2017;17(1): 527.

31 Balint M, Hunt J, Joyce D, Marinker M, Woodcock J. Treatment or diagnosis: a study of repeat prescriptions in general practice. London: Tavistock Publications; 1970.

32 Ribeiro MCSA. Perfil sociodemográfico e padrão de utilização de serviços de saúde para usuários e não usuários do SUS - Pnad 2003. Ciênc Saúde Colet. 2006;11(4): 1011-22.

33 Gouveia GC, Souza WV, Luna CF, SouzaJúnior PRB, Szwarcwald CL. Satisfação dos usuários do sistema de saúde brasileiro: fatores associados e diferenças regionais. Rev Bras Epidemiol. 2009;12(3): 281-96.

34 Silva LMP, Muccioli C, Belfort JR. Perfil socioeconômico e satisfação dos pacientes atendidos no mutirão de catarata do Instituto da Visão - UNIFESP. Arq Bras Oftalmol. 2004;67(5):737-44.

35 Sucupira AC. A importância do ensino da relação médico-paciente e das habilidades de comunicação na formação do profissional de saúde. Interface. 2007;11(23):624-7.
36 Sousa-Muñoz RL, Mendonça MS, Cruz V, Sales W, Pereira VE, Figueiredo AS. Satisfação do paciente idoso com internação em um hospital universitário. Rev Adm Saúde. 2017;17(68): 1-17.

37 Esperidião MA, Trad LAB. Avaliação de satisfação de usuários: considerações teóricoconceituais. Cad. Saúde Pública. 2006;22(6): 1267-76.

38 Jaipaul CK, Rosenthal GE. Are older patients more satisfied with hospital care than younger patients? J Gen Intern Med. 2003;18:23-30.

39 Barletta JB, Gennari MS, Cipolotti R. Perspectiva cognitivo-comportamental dos aspectos psicossociais que interferem na qualidade da relação médico-paciente. Psicol Rev. 2011;17(3): 396-413.

40 Ministério da Saúde (BR). Atenção especializada [Internet]; 2019 [citado 2019 mar 4]. Disponível em: http://portalms.saude.gov.br/ sistema-unico-de-saude/estrutura-do-sus/770sistema-nacional-de-saude/40317-atencaoespecializada

41 Bonato V. Gestão de qualidade em saúde: melhorando assistência ao cliente. Mundo Saúde. 2011;35(5):319-31.

42 Pinochet LHC, Galvão CR. Aspectos humanos na gestão hospitalar. Mundo Saúde. 2010;34(4):498-507.

43 Garneau K, Hutchinson T, Zhao Q, Dobkin PL. Cultivating person-centered medicine in future physicians. Eur J Pers Cent Healthc. 2013;1(2): 468-77.

44 Matthews DA, Sledge WH, Lieberman PB. Evaluation of intern performance by medical inpatients. Am J Med. 1987;35:936-44.

45 Ferreira DC, Souza ID, Assis CRS, Ribeiro MR. A experiência do adoecer: uma discussão sobre saúde, doença e valores. Rev Bras Educ Med. 2014;38(2):283-8.

46 Barros JAC. Pensando o processo saúde doença: a que responde o modelo biomédico? Saúde Soc. 2002;11(1): 67-84. 
47 Roter D, Hall J. Improving psychosocial problem address in primary care: is it possible and what difference does it make? Lecture of International Consensus Conference on Doctor-Patient Communication, Toronto, 1991 Nov 14-16.

48 Herzog R. A percepção de si como sujeito-dadoença. Physis. 1991;1(2): 143-55.

49 Pereira MGA, Azevêdo ES. A relação médicopaciente em Rio Branco/AC sob a ótica dos pacientes. Rev Assoc Med Bras. [Internet]. 2005 jun [citado 2019 maio 1];51(3): 1537. Disponível em: http://www.scielo.br/ scielo.php?script $=$ sci_arttext\&pid=S010442302005000300016\&lng $=$ en

50 Ferreira S. Reflexões sobre violência e poder na relação médico-paciente. Rev Saúde Dom Alberto. 2015;1(5): 32-40.

51 Wildevur SE, Thomese F, Ferguson J, Link A. Information and communication technologies to support chronic disease self-management: preconditions for enhancing the partnership in person-centered care. J Participat Med. 2017;9: e12.

52 Baronio M, Pecora AR. A relação de cuidado na perspectiva de médicos e pacientes durante a internação em hospital-escola. Psic Rev São Paulo. 2015;24(2):199-228.

53 Wen LS, Tucker S. What do people want from their health care? A qualitative study. J Participat Med. 2015;7: e10.

54 Vaitsman J, Andrade GRB. Satisfação e responsividade: formas de medir a qualidade e a humanização da assistência à saúde. Cien Saúde Colet. 2005;10(3): 599-613.

55 Gabutti I, Mascia D, Cicchetti A. Exploring "patient-centered" hospitals: a systematic review to understand change. BMC Health Serv Res. 2017;17(1): 364.

56 Cutolo LRA. Modelo biomédico, Reforma Sanitária e a educação pediátrica. ACM Arq Catarin Med [Internet]. 2006 [citado 2019 mar 5];35(4): 16-24. Disponível em: http://www. acm.org.br/revista/pdf/artigos/392.pdf
57 Nascimento Júnior PG, Guimarães TMM. A relação médico-paciente e seus aspectos psicodinâmicos. Bioética. 2003;11(1): 101-14.

58 Cruz CSS, Fernandes DRF, Martins SRR, Silva EJ, Silvério JB, Oliveira LC. A utilização do método clínico centrado na pessoa e a relação com a melhoria da performance clínica de médicos do programa de educação permanente para médicos da estratégia de saúde da família da região ampliada de saúde Jequitinhonha. Rev Saúde Púb SUS/MG. 2017;2(1): 105-14.

59 Ministério da Saúde (BR). Carta dos direitos dos usuários da saúde. Brasília: Ministério da Saúde; 2006.

60 Leite RAF, Brito ES, Silva LMC, Palha PF, Ventura CAA. Acesso à informação em saúde e cuidado integral: percepção de usuários de um serviço público. Interface [Internet]. 2014 [citado 2019 mar 4];18(51):66172. Disponível em: http://www.scielo.br/ scielo.php?script $=$ sci_arttext\&pid $=$ S1414$32832014000400661 \& \operatorname{lng}=$ en

61 O’Leary KJ, Kulkarni N, Landler MP, Jeon J, Hahn KJ, Englert KM, et al. Hospitalized patients' understanding of their plan of care. Mayo Clin Proc. 2010; 85(1): 47-52.

62 Arora V, Gangireddy S, Mehrotra A, Ginde R, Tormey M, Meltzer D. Research letters. Arch Intern Med. 2009;169(2):199-205.

63 Gulinelli A, Aisawa RK, Konno SN, Morinaga CV, Costardi WL, Antonio RO, et al. Desejo de informação e participação nas decisões terapêuticas em caso de doenças graves em pacientes atendidos em um hospital universitário. Rev Assoc Med Bras. [Internet]. 2004 [citado 2019 mar 5];50(1): 41-7. Disponível em: http:/www.scielo.br/ scielo.php?script $=$ sci_arttext\&pid $=$ S010442302004000100033\&lng=en

64 Nascimento GB, Henriques RSP. A exclusão do sujeito das práticas médicas em contexto hospitalar. Revista da SPAGESP [Internet]. 2015 [citado 2018 dez 6];16(2):120-35. Disponível em: http://pepsic.bvsalud.org/pdf/ rspagesp/v16n2/v16n2a10.pdf 
65 Bechel DL, Myers WA, Smith DG. Does patient-centered care pay off? Jt Comm J Qual Improv 2000;26(7): 400-9.

66 Sousa-Muñoz RL, De Sousa GB, De Brito CC, D'Paula B, Teixeira FS, Cabral RP. Conhecimento do consenso de sepse por médicos residentes de um hospital universitário. Ver Saúde. 2018;9(2): 9-15.

67 Sousa-Muñoz RL, Silva IBA, Maroja JLS. Experiência do estudante de semiologia médica em aulas práticas com o paciente à beira do leito. Rev Bras Educ Med. 2011;35(3): 376-81.

68 Caprara A, Rodrigues J. A relação assimétrica médico-paciente: repensando o vínculo terapêutico. Ciênc Saúde Colet. 2004;9(1): 139-46. 